\title{
Mechanical properties and chemical stability of pivalolactone-based poly(ether ester)s
}

\author{
E. J. Tijsma, L. van der Does* and A. Bantjes \\ Department of Chemical Technology, University of Twente, PO Box 217, \\ 7500 AE Enschede. The Netherlands \\ and I. Vulić \\ DSM Research, PO Box 18, 6160 MD Geleen, The Netherlands \\ (Received 23 December 1993; revised 20 May 1994)
}

\begin{abstract}
The processing, mechanical and chemical properties of poly(ether ester)s, prepared from pivalolactone (PVL), 1,4-butanediol (4G) and dimethyl terephthalate (DMT), were studied. The poly(ether ester)s could easily be processed by injection moulding, owing to their favourable rheological and thermal properties. The tensile response of a poly(ether ester) with a butylene terephthalate (4GT) content of $72 \mathrm{~mol} \%$, which exhibited the phenomena of necking and strain-hardening, was related to the morphology of these copolymers. The influence of the short $4 \mathrm{G}-\mathrm{PVL}$ segments was reflected in a high Young's modulus and yield stress, and resulted in a tough behaviour for the poly(ether ester), with an ultimate elongation of $500 \%$. The poly(ether ester)s were stable towards treatment at room temperature with water or weakly acidic or alkaline solutions. Conditioning at $90^{\circ} \mathrm{C}$ in water for $264 \mathrm{~h}$ resulted in a water uptake of $1 \mathrm{wt} \%$, whereas the rate of hydrolysis was 0.0003 (expressed in $\Delta \eta_{\text {rel }} \mathrm{h}^{-1}$ ) for the poly(ether ester) with a 4GT content of $72 \mathrm{~mol} \%$. Although a decay in the mechanical properties for the PVL-based poly(ether ester) after exposure to water at $90^{\circ} \mathrm{C}$ was observed, these materials were assumed to have a higher hydrolytical stability than other poly(ether ester)s.
\end{abstract}

(Keywords: pivalolactone; poly(ether ester)s; processing)

\section{INTRODUCTION}

Poly(ether ester)s are usually prepared by a two-stage melt transesterification process from readily available starting materials such as dimethyl terephthalate (DMT), an alkanediol $(n \mathrm{G})$ and a poly(alkylene glycol ether $)^{1,2}$. The resulting poly(ether ester)s consist of sequences of crystallizable alkylene terephthalate $(n \mathrm{GT})$ sequences and elastomeric poly(alkylene oxide) (POn) segments. Using the notation proposed by Perego et al..$^{3}$, the chemical structure of these materials can be represented by the following:

$$
\left[(n \mathrm{GT})_{k}-\mathrm{PO} n\right]_{z}
$$

in which $k$ is the number-average $n \mathrm{GT}$ sequence length. These materials show a wide range of properties ${ }^{4,5}$ depending upon the amount of $n \mathrm{GT}$ segments and the length of the POn unit. Several commercially available block poly(ether ester)s, based on butylene terephthalate (4GT) and poly(tetramethylene oxide) (PO4) are known, such as Hytrel ${ }^{\mathrm{H}}$ (DuPont) and Arnitel ${ }^{\overline{\mathrm{A}}}$ (DSM). These materials combine many interesting properties, including a high melting temperature $T_{\mathrm{m}}$, a low glass temperature $T_{\mathrm{g}}$, and high yield stress, ultimate elongation and elasticity, along with ease of processing. However, one of the disadvantages of the incorporation of PO4 in these poly(ether ester)s is the relatively low stability that is

\footnotetext{
* To whom correspondence should be addressed
}

found $^{4}$, e.g. with respect to hydrolysis at increased temperatures.

As we have reported earlier, poly(ether ester)s based on pivalolactone (PVL) were obtained by the reaction of mixtures of PVL, $n \mathrm{G}$ and DMT via a two-stage melt process ${ }^{6}$. Using the above notation, the structure of PVL-based poly(ether ester)s as presented in Scheme 1 can be represented by the following:

$$
\left[(n \mathrm{GT})_{k}-n \mathrm{G}-\mathrm{PVL}\right]_{z}
$$

Polymerization of PVL, $n \mathrm{G}$ and DMT via a two-stage melt process in a batch reactor $(\sim 1000 \mathrm{~g})$ yielded
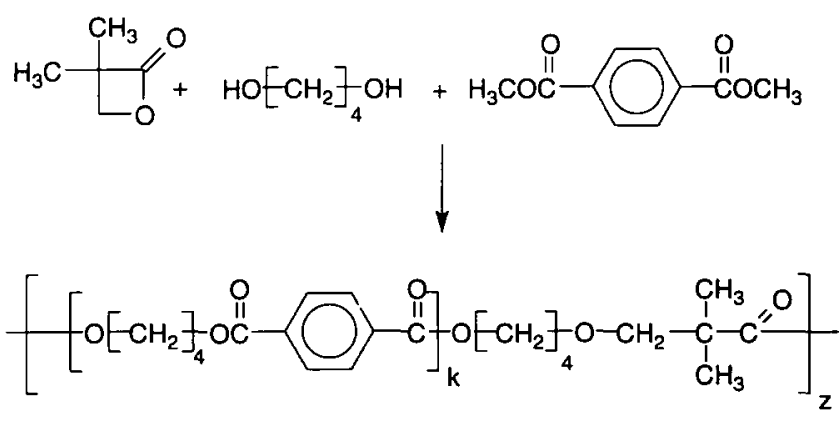

4G $\quad \mathrm{T} \quad 4 \mathrm{G} \quad$ PVL

Scheme 1 The synthesis of PVL-based poly(ether ester)s via a two-stage melt process 
poly(ether ester)s with molecular weights $M_{\mathrm{n}} \geqslant 10000^{7}$. Besides the ease of manufacturing, the PVL-based poly(ether ester)s had interesting thermal properties ${ }^{7}$, indicating that this process shows promise for developing new engineering plastics on an industrial scale. Therefore, these materials were investigated in more detail, and in particular their processing, mechanical properties and chemical stability was studied. In this paper, data on these properties are presented and a comparison is also made between the properties of the PVL-based poly(ether ester)s and those of polyesters and other poly(ether ester)s.

It should be noted that a comparison of the PVL-based poly(ether ester)s with $n \mathrm{GT}$-POn-based poly(ether ester)s was made only because of their comparable chemical structures, i.e. with both containing $n \mathrm{GT}$ sequences and ether bonds, although the microstructures of these two types of copolymers are clearly different.

\section{EXPERIMENTAL}

\section{Materials}

Pivalolactone (PVL) was purified as described earlier ${ }^{6}$. Dimethyl terephthalate (DMT), 1,4-butanediol (4G) and tetrabutylorthotitanate (TnBT) were obtained from Merck and were used as received. Chloroform (Merck) and $m$-cresol (Merck) were used without further purification. Ethanol and methanol, used for precipitation, were of technical grade. Poly(butylene terephthalate) (PBT, Arnite $^{\mathrm{R}}$ T04-200, DSM) was used as received.

\section{Symthesis of PVL-based poly(ether ester)s}

Small-scale polymerizations (up to $25 \mathrm{~g}$ of polymer) were carried out in a $50 \mathrm{ml}$ reaction vessel as described earlier ${ }^{6}$. Poly(ether ester)s were prepared on a large scale in a stainless steel batch reactor (up to $1000 \mathrm{~g}$ of polymer) of a general type used for poly(alkylene terephthalate) synthesis. In a typical large-scale polymerization (see Table I, sample P4GT-70/11), PVL (70.0 g, $0.70 \mathrm{~mol})$, DMT $(317 \mathrm{~g}, 1.63 \mathrm{~mol}), 4 \mathrm{G}(294 \mathrm{~g}, 3.27 \mathrm{~mol})$ and TnBT $(0.1 \mathrm{wt} \%)$ were placed in the reactor. After $2 \mathrm{~h}$ of stirring (100 rev $\min ^{-1}$ ) at $200^{\circ} \mathrm{C}$, during which the methanol that was formed was distilled out, the temperature was raised to $250^{\circ} \mathrm{C}$ over a period of $30 \mathrm{~min}$. In the second stage of the reaction, a vacuum ( $20 \mathrm{mbar}$ ) was applied for $30 \mathrm{~min}$ and polymerization was completed by stirring $\left(50 \mathrm{rev} \mathrm{min}^{-1}\right)$ at $250^{\circ} \mathrm{C}$ and $1 \mathrm{mbar}$ for $2.5 \mathrm{~h}$, during which the torque measured increased from 0.1 to $0.5 \mathrm{Nm}$. Next, the clear viscous melt was removed from the reactor by pressing it through a bottom valve using a small overpressure. The clear polymer fibre was cooled in a water bath and then wound upon a spool. After chipping and drying, about $400 \mathrm{~g}$ of a polymer was obtained $\left([\eta]=0.47 \mathrm{dl} \mathrm{g}^{-1}\right.$ in chloroform).

\section{Processing}

Before processing, the poly(ether ester)s were dried for $6 \mathrm{~h}$ (in vacuo at $120^{\circ} \mathrm{C}$ ). Poly(ether ester)s were injection moulded into test bars, for characterization of mechanical properties, on an extruder (Arburg 220-90-350), using the following conditions: temperature $215-225^{\circ} \mathrm{C}$, screw speed $200 \mathrm{rev} \mathrm{min}^{-1}$ and throughput $60 \mathrm{~g} \mathrm{~h}^{-1}$.

\section{Characterization}

Chemical stability. The stability of the PVL-based poly(ether ester)s was examined by conditioning test bars at room temperature in water and in $10 \%$ aqueous solutions of $\mathrm{NaOH}$ and $\mathrm{H}_{2} \mathrm{SO}_{4}$, and at $90^{\circ} \mathrm{C}$ in water for several days. Apart from evaluating the mechanical properties (tensile properties and Shore-D hardness), the changes in weight and in $\eta_{\text {rel }}$ were also measured.

Mechanical properties. Dynamic melt viscosity measurements were performed at various temperatures on a Rheometrics RMS 800 machine with a cone-andplate geometry; the angular velocity of the cone, which was proportional to the shear rate, was varied from 1.6 to $160 \mathrm{rad} \mathrm{s}^{-1}$.

Tensile properties were tested under standard conditions (ISO-R527) in a Zwick 1455 machine at a testing speed of $50 \mathrm{~mm} \mathrm{~min}^{-1}$. The Shore-D hardness was measured according to ISO-R868 in a Zwick Shore-D apparatus (Type 1008.56a). The heat deflection temperature (HDT) was determined under standard conditions (ISO-75) using a nominal surface stress of $1.8 \mathrm{MPa}(\operatorname{method} \mathrm{A})$. The Izod

Table 1 Characteristics of PVL-based poly(ether ester)s (small-scale polymerization) obtained under the following general conditions: $3 \mathrm{~h}, 200-250^{\circ} \mathrm{C}$, $\mathrm{N}_{2}: 2 \mathrm{~h}, 250^{-} \mathrm{C}, 0.1 \mathrm{mbar}$

\begin{tabular}{|c|c|c|c|c|c|c|c|}
\hline \multirow[b]{2}{*}{ Sample } & \multicolumn{3}{|c|}{$\begin{array}{l}\text { Composition } \\
(\mathrm{mol} \%)\end{array}$} & \multirow{2}{*}{$\begin{array}{l}{[\eta]^{b}} \\
\left(\mathrm{dl} \mathrm{g}^{-1}\right)\end{array}$} & \multirow{2}{*}{$\begin{array}{l}M_{n}^{c . d} \\
\left(\times 10^{-3}\right)\end{array}$} & \multirow{2}{*}{$\begin{array}{c}T_{\mathrm{m}}^{\mathrm{e}} \\
\left({ }^{\circ} \mathrm{C}\right)\end{array}$} & \multirow{2}{*}{$\begin{array}{l}T_{c} \\
\left({ }^{\circ} \mathrm{C}\right)\end{array}$} \\
\hline & PVL & $4 \mathrm{G}$ & $\mathrm{T}$ & & & & \\
\hline P4GT-30/01 & 41 & 41 & 18 & 0.08 & $1.1^{d}$ & liq & - \\
\hline P4GT-40/01 & 32 & 44 & 24 & 0.13 & $2.5^{d}$ & liq & - \\
\hline P4GT-50/01 & 25 & 47 & 28 & 0.29 & $8.8^{d}$ & 117 & 50 \\
\hline P4GT-60/01 & 19 & 49 & 32 & 0.42 & $16^{c}$ & 143 & 98 \\
\hline P4GT-70/01 & 13 & 51 & 36 & 0.49 & $21^{d}$ & 177 & 130 \\
\hline P4GT-70/11 $f$ & 14 & 50 & 36 & 0.47 & $20^{d}$ & 175 & 126 \\
\hline P4GT-80/01 & 8 & 52 & 41 & ns & - & 200 & 157 \\
\hline P4GT-90/01 & 3 & 49 & 48 & ns & - & 210 & 177 \\
\hline
\end{tabular}

${ }^{a}$ Determined from 'H n.m.r. spectra in deuterated chlorolorm or trifluoroacetic acid

"Determined in chloroform at $25^{\circ} \mathrm{C}\left(c=0.50 \mathrm{~g} \mathrm{dl}^{-1}\right)$; ns= not soluble in chloroform

'Determined from s.e.c. measurements (Ref. 7)

${ }^{d}$ Calculated using $[\eta]=5.2 \times 10^{-4} M_{w}^{0.62}$ and $M_{w} / M_{n}=3(\operatorname{Ref} .7)$

'Determined from d.s.c. measurements; liq = viscous liquid at room temperature

${ }^{f}$ Large-scale polymerization 
impact strength was measured at $-10,0$ and $23^{\circ} \mathrm{C}$, using notched test bars.

Dynamic mechanical analysis (d.m.a.) was carried out in a torsion pendulum instrument by heating torsion bars from $-80^{\circ} \mathrm{C}$ to the onset of melting, at a heating rate of $2^{\circ} \mathrm{C} \mathrm{min}^{-1}$ and at a frequency of $0.2 \mathrm{~Hz}$.

Measurements. Viscometry measurements were carried out in chloroform $\left(c=0.50 \mathrm{~g} \mathrm{dl}^{-1}\right)$, using an Ubbelohde viscometer thermostatted at $25^{\circ} \mathrm{C}$. In the case of PBT, $m$-cresol $\left(c=0.10 \mathrm{~g} \mathrm{dl}^{-1}\right)$ was used. The limiting viscosity number $[\eta]$ was determined at one concentration using an equation derived by Raju and Yaseen ${ }^{8}$, as follows:

$$
\log [\eta]=\log \left[\left(\eta_{\text {rel }}-1\right) / c\right]-K\left(\eta_{\text {rel }}-1\right)
$$

in which $\eta_{\text {rel }}$ and $c$ are the relative viscosity and the concentration of polymer in the solvent (in $\mathrm{g} \mathrm{dl}^{-1}$ ), respectively. This equation could be used according to Raju and Yaseen ${ }^{8}$ when $K=0.14$ for $\left(\eta_{\text {rel }}-1\right)<0.3$ and $K=0.12$ for $0.3<\left(\eta_{\mathrm{rcl}}-1\right)<0.8$. The applicability of this method was tested by comparison with the $[\eta]$ values obtained by extrapolation to zero concentration. In all cases, differences between the results remained within experimental error. ${ }^{1} \mathrm{H}$ n.m.r. spectra were recorded on a Bruker AC $250 \mathrm{~F}$ spectrometer using deuterated chloroform or trifluoroacetic acid. Size exclusion chromatography (s.e.c.), d.s.c. and t.g.a. measurements were carried out as described earlier ${ }^{7}$.

\section{RESULTS AND DISCUSSION}

\section{Copolymer synthesis}

Polymers were synthesized by the simultaneous condensation and ring-opening polymerization of PVL, 4G and DMT in the presence of TnBT (see Table l). In these syntheses, $x \mathrm{~mol}$ of PVL, $y \mathrm{~mol}$ of DMT and $2 y \mathrm{~mol}$ of $4 \mathrm{G}$ were reacted in the melt. During the first stage of the reaction between PVL, $4 \mathrm{G}$ and DMT $\left(200^{\circ} \mathrm{C}\right)$ almost quantitative amounts of methanol were formed, indicating the occurrence of ester interchange as the initial step. Apart from interchange reactions, initiation of PVL polymerization involving ring opening took place. In spite of the relatively low boiling point of PVL $\left(110^{\circ} \mathrm{C}\right)$ no significant loss of lactone was observed. In the second stage, polymerization was completed under vacuum after the temperature had been increased to $250^{\circ} \mathrm{C}$.

The characteristics of the polymers synthesized by this two-stage process from PVL, DMT and $4 \mathrm{G}$ are presented in Table 1 . Most of the polymers were soluble in chloroform, a solvent in which neither polypivalolactone (PPVL) nor the corresponding poly(alkylene terephthalate)s were soluble. The compositions of the various copolymers, listed in Table 1 , were calculated from ${ }^{1} \mathrm{H}$ n.m.r. spectroscopic data. As an example, the ${ }^{1} \mathrm{H}$ n.m.r. spectrum of sample P4GT-50/01 (see Table l) is presented in Figure 1. Using the peaks I-III (as shown in the figure) the composition of the copolymers could be calculated. Peak I was assigned to aromatic protons of the terephthalate (T) unit and peak II to the $\mathrm{C} 2$ and $\mathrm{C} 3$ protons of the butylene unit, while peak III corresponded to the methyl protons of the PVL unit. A more detailed n.m.r. spectroscopic study has been given in our previous paper ${ }^{6}$, in which the microstructure of the PVL-based poly(ether ester)s was elucidated. Furthermore, the morphology of these poly(ether ester)s could be described as a crystalline $4 \mathrm{GT}$ phase and an amorphous phase consisting of a mixture of $n \mathrm{G}-\mathrm{PVL}$ units and noncrystallized 4GT segments ${ }^{7}$.

The synthesis of poly(ether ester)s from PVL, $4 G$ and DMT resulted in copolymers with a broad range of values of $[\eta]$ (as shown in Table I). From the viscometry results, single-point $[\eta]$ values were determined according to the method developed by Raju and Yaseen ${ }^{8}$. S.e.c. experiments were carried out in methylene chloride to determine the molecular weights of the PVL-based poly(ether ester)s. From a double logarithmic plot of $[\eta]$ versus the weight-average molecular weights (determined by s.e.c.) the Mark-Houwink constants could be calculated, as reported in our previous paper ${ }^{7}$; the equation derived from the viscometry measurements in chloroform at $25^{\circ} \mathrm{C}$ can be written as follows:

$$
[\eta]=5.2 \times 10^{-4} M_{\mathrm{w}}^{0.62}
$$

\section{Processing}

To determine the mechanical properties of the PVLbased poly(ether ester)s, several of these copolymers were studied further (see Table 1, samples P4GT-50/01, -60/01 and -70/01). These three copolymers were chosen, as the materials covered a wide range of properties, e.g. $T_{\mathrm{m}}$ and molecular weight. Furthermore, from Table $l$ it can be seen that the poly(ether ester)s with a PVL content above $30 \mathrm{~mol} \%$ had no $T_{\mathrm{m}}$ above room temperature, whereas those materials with a PVL content below $10 \mathrm{~mol} \%$ were not soluble in common solvents.

Information concerning the processing parameters for PVL-based poly(ether ester)s may be obtained from rheological measurements and thermal analysis studies. Therefore, the melt viscosity was investigated and in Figure 2 the latter is plotted versus the angular velocity of the cone. From this figure it can be seen that the melt viscosity was independent of the angular velocity, indicating that these poly(ether ester)s may be considered as being Newtonian in behaviour. The melt viscosity was also studied as a function of temperature and from Figure 3 and Table 1 it can be seen that the melt viscosities increased with molecular weight. However, even the two

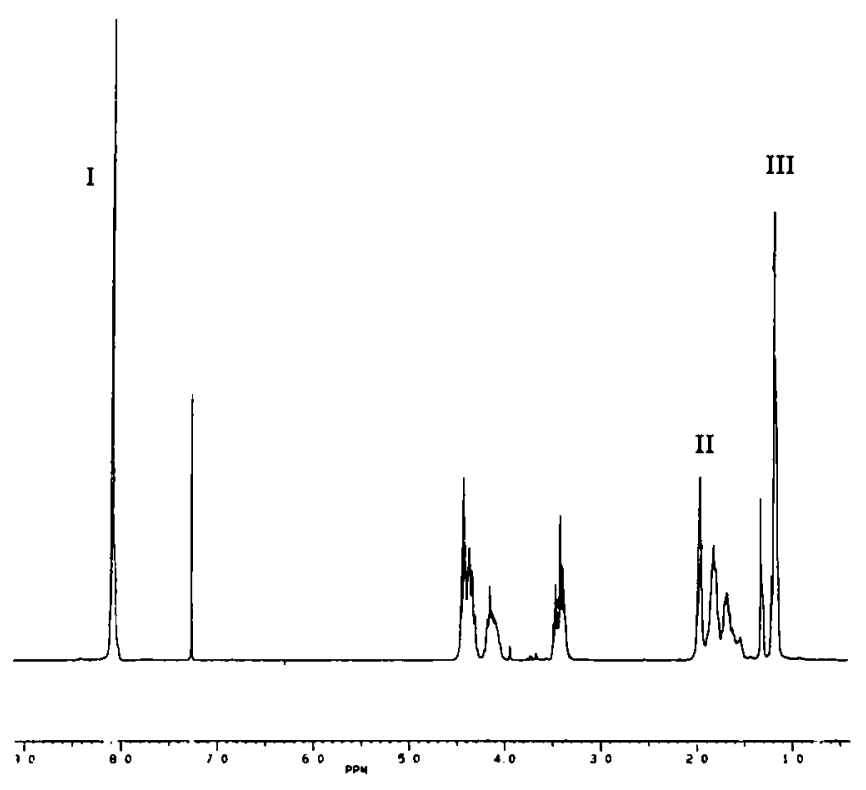

Figure $1{ }^{1} \mathrm{H}$ n.m.r. spectrum of a copolymer synthesized from PVL, $4 \mathrm{G}$ and DMT (Table I, sample P4GT-50/01) 


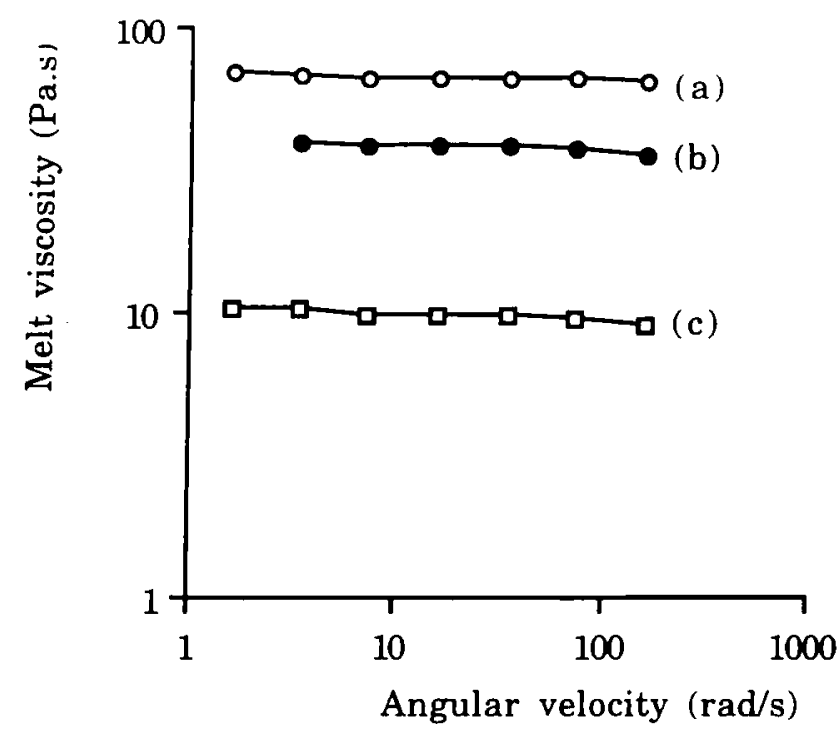

Figure 2 Melt viscosity versus angular velocity for PVL-based poly(ether ester)s: (a) P4GT-70/01 at $200^{\circ} \mathrm{C}$; (b) P4GT-60/0I at $170^{\circ} \mathrm{C}$; (c) P4GT-50/01 at $150^{\circ} \mathrm{C}$

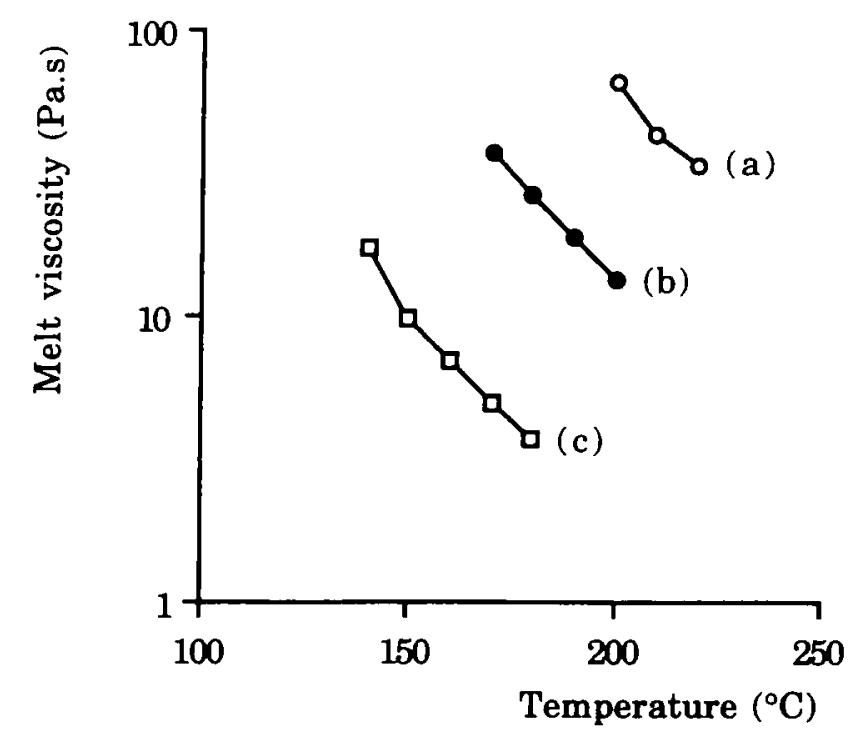

Figure 3 Melt viscosity rersus temperature for PVL-based poly(ether ester)s: (a) P4GT-70/01; (b) P4GT-60/01: (c) P4GT-50/01

copolymers with relatively high molecular weights, i.e. $M_{\mathrm{n}} \geqslant 10000$ (P4GT-60/01 and -70/01), displayed lower melt viscosities than the PO4-based poly(ether ester)s, which have values which are well above $100 \mathrm{~Pa}$ s. On the other hand, these relatively low melt viscosities may be advantageous as far as processing of these copolymers is concerned. Therefore, it was assumed that it should be possible to process PVL-based poly(ether ester)s by injection moulding, as the melt viscosity range required for injection moulding is from 50 to $500 \mathrm{~Pa} \mathrm{~s}$.

The thermal properties of PVL-based poly(ether ester)s were studied by d.s.c. and t.g.a. Values of $T_{\mathrm{m}}$ and the crystallization temperature $T_{\mathrm{c}}$ are presented in Table $l$ and by comparing these two temperatures, a measure for the rate of crystallization was obtained. The copolymers showed a supercooling of $40-60^{\circ} \mathrm{C}$, which was comparable with other 4GT-based poly(ether ester) ${ }^{4}$, such as Hytrel ${ }^{\mathrm{R}}$ and Arnitel ${ }^{\mathrm{R}}$. PVL-based poly(ether ester)s were thermally stable up to temperatures well above $T_{m}$, irrespective of the proportion of PVL units in the copolymers, as has been shown already in a previous paper $^{\text {? }}$. The PVL-based poly(ether ester) P4GT-70/01 showed a melting range of $140-190^{\circ} \mathrm{C}$, which determined the minimum processing temperature, whereas the crystallization range $\left(100-150^{\circ} \mathrm{C}\right)$ defined the mould temperature to be used. Furthermore, P4GT-70/01 was stable up to $280-300^{\circ} \mathrm{C}$, thus determining the maximum processing temperature.

Based on the rheological and thermal data reported above, the copolymer with both the highest $T_{m}$ and molecular weight, i.e. P4GT-70/01, was selected to be studied in more detail. Using the large-scale procedure, a copolymer with the same characteristics as P4GT-70/01 was obtained (see Table l, sample P4GT-70/11), and injection moulding was performed with this copolymer. From Table 2 it can be seen that the processing conditions for the PVL-based and a typical PO4-based poly(ether ester) were comparable; the only difference being that the pressure needed for injection was higher for the latter, thus reflecting the higher melt viscosity of the PO4-based copolymer ${ }^{4}$. Applying the conditions as presented in Table 2 resulted in mouldings for the PVL-based poly(ether ester) which showed no sink marks and were only somewhat flashy.

\section{Mechanical properties}

Curve (a) in Figure 4 shows the stress-strain curve of P4GT-70/11 and, for comparison, the stress-strain curves of a number of 4GT-PO4-based poly(ether ester)s ( Hytrel $^{\mathrm{R}}$ ) with various $4 \mathrm{GT}$ contents are included in this figure 4 . From the compositional data of P4GT-70/11 (Table 1 ) and its chemical structure (Scheme 1), it followed thatP4GT-70/11 had a 4GT content of $72 \mathrm{~mol} \%$. As far as this copolymer was concerned, three distinct regions could be seen in the stress-strain curve. First, a linear relationship was observed between the stress applied and the resulting strain, and after reaching a maximum value, the stress dropped. Next, the strain increased with almost constant stress and accompanying neck formation. At a strain of $350 \%$, a higher strain was obtained by a sudden increase in stress; double neck formation then occurred, ultimately leading to break.

To explain the tensile response of the PVL-based poly(ether ester), which displays phenomena such as necking and cold-drawing, the structure of these copolymers

Table 2 Injection moulding conditions for poly(ether ester)s

\begin{tabular}{lll}
\hline & \multicolumn{2}{c}{ Poly(ether ester) } \\
\cline { 2 - 3 } Condition property & $\begin{array}{c}\text { PVL-based } \\
\text { (P4GT-70/11) }\end{array}$ & $\begin{array}{l}\text { PO4-based } \\
\text { (Arnitel " EM 460') }\end{array}$ \\
\hline$T_{\mathrm{m}}$ ( C) & 175 & 185 \\
Cylinder temperature ( $\mathrm{C}$ ) & & \\
Zone 1 & 215 & 210 \\
Zone 2 & 225 & 210 \\
Zone 3 & 225 & 215 \\
Melt temperature ( C) & 225 & 220 \\
Mould temperature ( C) & 20 & 50 \\
Injection pressure (MPa) & 2 & 80 \\
Back pressure (MPa) & 0.2 & 6 \\
Injection +holding time (s) & 15.2 & 15 \\
Cooling time (s) & 20 & 13 \\
Plasticizing time (s) & 3.1 & 12 \\
Total cycle time & 38.3 & 38 \\
\hline
\end{tabular}

"Data according to Quirk et al. 
must be considered. In our earlier paper, it was demonstrated that these poly(ether ester)s consisted mainly of two units ${ }^{6}$, i.e. $4 \mathrm{GT}$ and $4 \mathrm{G}-\mathrm{PVL}$ units. Furthermore, it was shown that the structure of the copolymers could be described as consisting of crystalline alkylene terephthalate $(n \mathrm{GT})$ sequences and a mixture of amorphous $n \mathrm{G}-\mathrm{PVL}$ units and non-crystallized $n \mathrm{GT}$ segments ${ }^{7}$. In PO4-based poly(ether ester)s, such as Hytrel $^{\mathrm{H}}$ and Arnitel ${ }^{\mathrm{R}}$, the crystallizable segments also consist of sequences of 4GT units, whereas the long-chain PO4 segments form elastomeric segments.

The explanation of the stress-strain curves of the PO4-based copolymers, as shown in Figure 4, was given by Schroeder and Cella ${ }^{4}$. The high Young's modulus and yield stress (see Figure 4 and Table 3) were proposed to be due to deformation of the crystalline matrix and of short non-crystallized 4GT segments, i.e. the so-called tie molecules. This would suggest that the Young's modulus and yield stress increase with 4GT content, which is the case as can be seen in Figure 4 and Table 3. At low elongations, these tie molecules quickly approach their fully extended length, resulting in a high Young's modulus. After the tie molecules have reached full

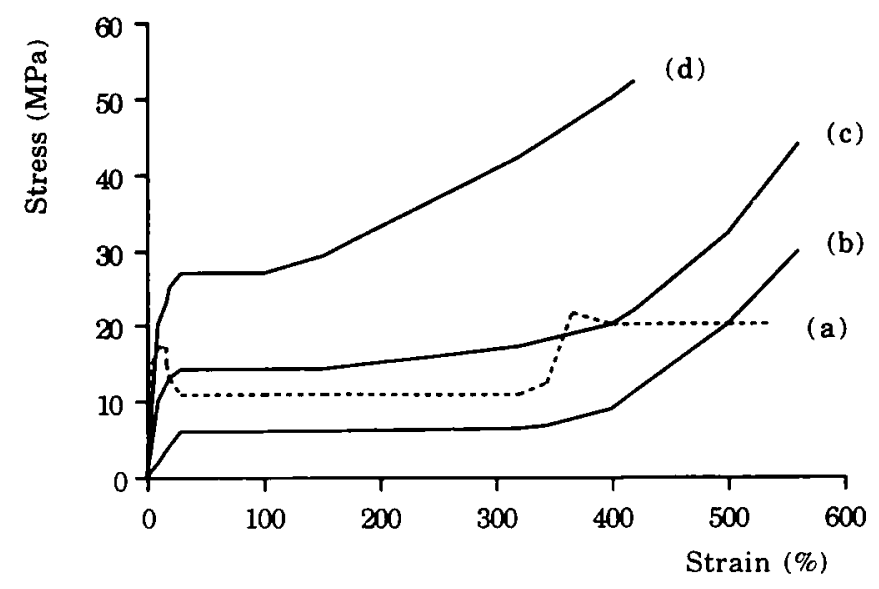

Figure 4 Stress-strain curves of (a) P4GT-70/11 (72 mol\% 4GT) and of various PO4-based poly(ether ester)s (Hytrel ")": (b) 70 ; (c) 87 ; (d) $95 \mathrm{~mol} \% 4 \mathrm{GT}$ extension, the crystalline matrix starts to orient and when the crystallites have become oriented, stress is transferred to the elastomeric PO4 network. Finally, these long amorphous segments show large deformations, resulting in break at ultimate elongations higher than $500 \%$.

The high Young's modulus and yield stress of P4GT-70/11 reflected the resistance against quasi-elastic deformation of the crystalline matrix consisting of $4 \mathrm{GT}$ sequences and its tie molecules, i.e. non-crystallized 4GT segments. Although the initial stress-strain behaviour of the PVL-based poly(ether ester) qualitatively resembled that of the PO4-based polymer, it can be seen from Figure 4 and Table 3 that P4GT-70/11 possessed a higher Young's modulus and yield stress when compared with the PO4-based poly(ether ester) with the same 4GT content. Although the exact origin of this behaviour is not clear, the large force required to orient the crystalline 4GT sequences, resulting in a high Young's modulus, may be due to the presence of the short $4 \mathrm{G}-\mathrm{PVL}$ segments.

At higher strains, orientation in the PVL-based poly(ether ester) occurred and stress was transferred completely to the relatively short $n \mathrm{G}-\mathrm{PVL}$ segments present, which probably required a lower force for deformation. The so-called strain-hardening effect at a strain of $350 \%$ for P4GT-70/11 occurred along with a further deformation of the test bars (double neck formation). The resulting sudden increase in stress, which was not observed in the stress-strain curves of the PO4-based poly(ether ester)s, may be due to the fact that the short $4 \mathrm{G}-\mathrm{PVL}$ segments were not able to transmit the stress applied, resulting in a growing orientation and some further, stress-induced, crystallization. Again, due to the short $4 \mathrm{G}-\mathrm{PVL}$ segments, lower stresses were required to result in breakage of the material.

It should be emphasized that the PVL-based poly(ether ester)s could only be compared on a qualitative basis with the PO4-based polymers, because the microstructures of these two types of copolymers are quite different. In contrast to the PO4-based poly(ether ester)s, which do contain long (POn-) sequences forming an elastomeric network, P4GT-70/11 did not show any typical elastomeric behaviour, as can be seen from Figure 4.

Table 3 Mechanical properties of poly(ether ester)s $\mathbf{s}^{\mathbf{a}}$

\begin{tabular}{|c|c|c|c|c|c|}
\hline \multirow[b]{3}{*}{ Condition/property } & \multirow{3}{*}{$\begin{array}{l}\text { PVL-based } \\
\text { (P4GT-70/11) }\end{array}$} & \multicolumn{4}{|c|}{ PO4-based } \\
\hline & & \multicolumn{3}{|c|}{ Hytrel" } & \multirow{2}{*}{$\begin{array}{l}\text { Arnitel " } \\
\text { (EM 460) }\end{array}$} \\
\hline & & G 4056 & G 5556 & G 7246 & \\
\hline 4GT content (mol\%) & 72 & 70 & 87 & 95 & na \\
\hline $\begin{array}{l}T_{m}(\cdot \mathrm{C}) \\
\text { Peak }\end{array}$ & 175 & 145 & 201 & 217 & na \\
\hline Melt complete & 190 & 170 & 220 & 232 & 185 \\
\hline Young's modulus (MPa) & 344 & 48 & 207 & 517 & 100 \\
\hline Yield stress (MPa) & 17 & 5 & 14 & 25 & na \\
\hline Ultimate elongation $(\%)$ & 500 & 560 & 560 & 420 & 700 \\
\hline Tensile strength (MPa) & 20 & 30 & 44 & 52 & 21 \\
\hline Shore-D hardness & 50 & 40 & 55 & 72 & 45 \\
\hline $\begin{array}{l}H D T(\mathrm{C}) \\
1.8 \mathrm{MPa}\end{array}$ & 40 & na & 49 & 50 & na \\
\hline $0.46 \mathrm{MPa}$ & na & 54 & 101 & 140 & na \\
\hline
\end{tabular}

"Data for Hytrel" from Schroeder and Cella ${ }^{4}$ and for Arnitel " from Quirk et al. ${ }^{5} ;$ na $=$ not available 
Several other mechanical properties of the poly(ether ester)s are listed in Table 3. With respect to hardness and $H D T$, the same values were obtained for the PVL- and PO4-based copolymers with the same 4GT contents. Furthermore, at $23^{\circ} \mathrm{C}$ the test bars did not break during an Izod impact strength test, also indicating the ductile behaviour of P4GT-70/11. However, when performing the tests at 0 and $-10^{\circ} \mathrm{C}$, the test bars did break and values were obtained for the Izod impact strength of 1.6
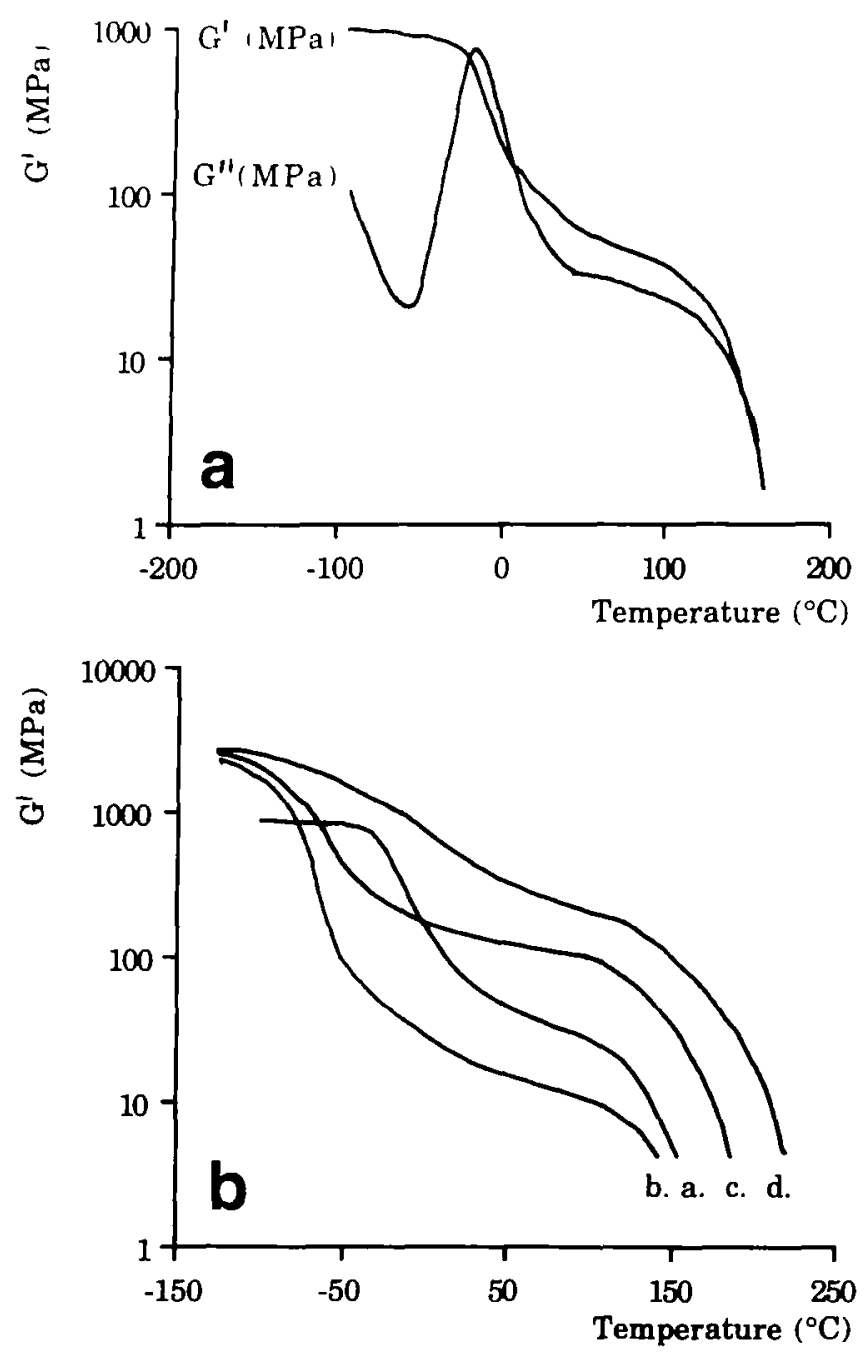

Figure 5 (a) Dynamic storage $\left(G^{\prime}\right)$ and loss $\left(G^{\prime \prime}\right)$ moduli of P4GT-70/11. (b) Dynamic storage moduli ( $G^{\prime}$ s) of (a) P4GT-70/11 and of PO4-based poly(ether ester) ${ }^{4}:$ (b) 70 : (c) 87 ; (d) $95 \mathrm{~mol} \%$ 4GT

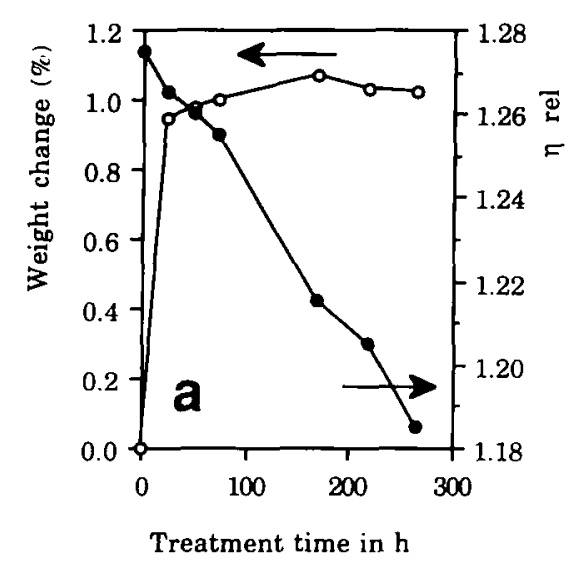

Figure 6 Water uptake and $\eta_{\text {rel }}$ versus water treatment time at $90^{\circ} \mathrm{C}$ : (a) P4GT-70/11; (b) PBT

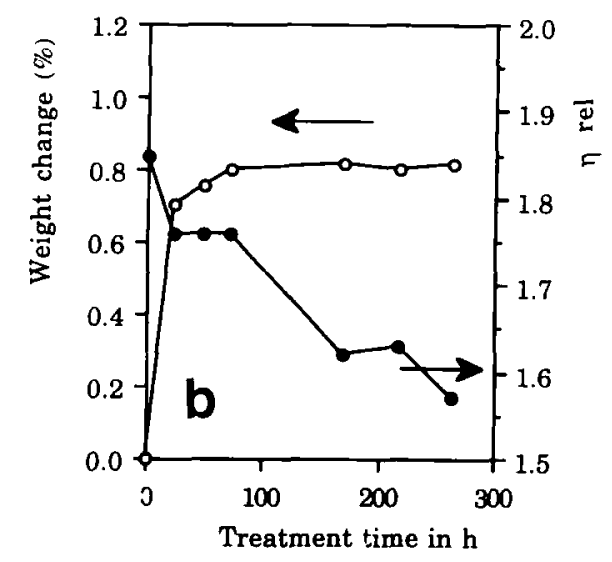

and $1.5 \mathrm{~kJ} \mathrm{~m}^{-2}$, respectively. This is in accordance with the fact that brittleness is governed by $T_{g}$, which was $5^{\circ} \mathrm{C}$ for this copolymer, according to d.s.c. measurements. In contrast to the PVL-based poly(ether ester), the PO4based polymers did not break during an Izod impact strength test at any of these temperatures, which reflected their low $T_{\mathrm{g}}$ values, e.g. Hytrel ${ }^{\mathrm{R}} \mathrm{G} 4056$ has a $T_{\mathrm{g}}$ below $-70^{\circ} \mathrm{C}$.

Figure $5 a$ shows the storage $\left(G^{\prime}\right)$ and loss $\left(G^{\prime \prime}\right)$ moduli of P4GT-70/11, while Figure $5 b$ gives the storage moduli of several PO4-based poly(ether ester)s for comparison. The curve of the storage modulus of the PVL-based poly(ether ester) displayed a rubber plateau, which remained fairly constant over a temperature range of $\sim 100^{\circ} \mathrm{C}$ and decreased over a short range near the $T_{\mathrm{m}}$ of P4GT-70/11 (i.e. $170^{\circ} \mathrm{C}$ ). This behaviour was comparable with the behaviour of, e.g. Hytrel ${ }^{\mathrm{R}} \mathrm{G} 4056$ with the same $4 \mathrm{GT}$ content (Figure $5 b$, curve (b)). Typical values for $G^{\prime}\left(30^{\circ} \mathrm{C}\right)$ of the PO4-based poly(ether ester)s ranged from 50 to $600 \mathrm{MPa}$, with increasing 4GT content ${ }^{4}$. P4GT-70/11, containing $72 \mathrm{~mol} \% 4 \mathrm{GT}$, showed a value for $G^{\prime}\left(30^{\circ} \mathrm{C}\right)$ of $110 \mathrm{MPa}$. The loss modulus of P4GT-70/11 showed a single sharp maximum at $6^{\circ} \mathrm{C}$, which corresponded to the $T_{\mathrm{g}}$ of $5^{\circ} \mathrm{C}$, as determined by d.s.c.

\section{Chemical stability}

IJzermans et al. made an exploratory investigation of the properties of PO4-based poly(ether ester)s and claimed that a 4GT-PO4-based poly(ether ester) with a 4GT content of $\sim 87 \mathrm{~mol} \%$ was more stable towards degradation in boiling water than PBT and poly(ethylene terephthalate) $)^{9}$. However, in contrast to the results of IJzermans et al. ${ }^{9}$, the chemical stability of the PO4-based poly(ether ester)s is now considered to be inferior to that of $\mathrm{PBT}^{4}$. The chemical stability of PVL-based poly(ether ester)s and the changes in mechanical properties were studied and the results obtained were related to those determined for PBT. First, the chemical stability of the PVL-based poly(ether ester)s was studied by exposure to various media. Treatment with water and $10 \%$ solutions of $\mathrm{NaOH}$ and $\mathrm{H}_{2} \mathrm{SO}_{4}$ at room temperature did not result in any significant weight changes. It has been reported that polypivalolactone (PPVL) showed a water uptake of $0.22 \mathrm{wt} \%$ after $264 \mathrm{~h}$ of treatment with water at room temperature ${ }^{10}$.

In Figure 6 , the water uptake and decrease in $\eta_{\text {rel }}$ of P4GT-70/11 and PBT, after treatment with water at $90^{\circ} \mathrm{C}$, 

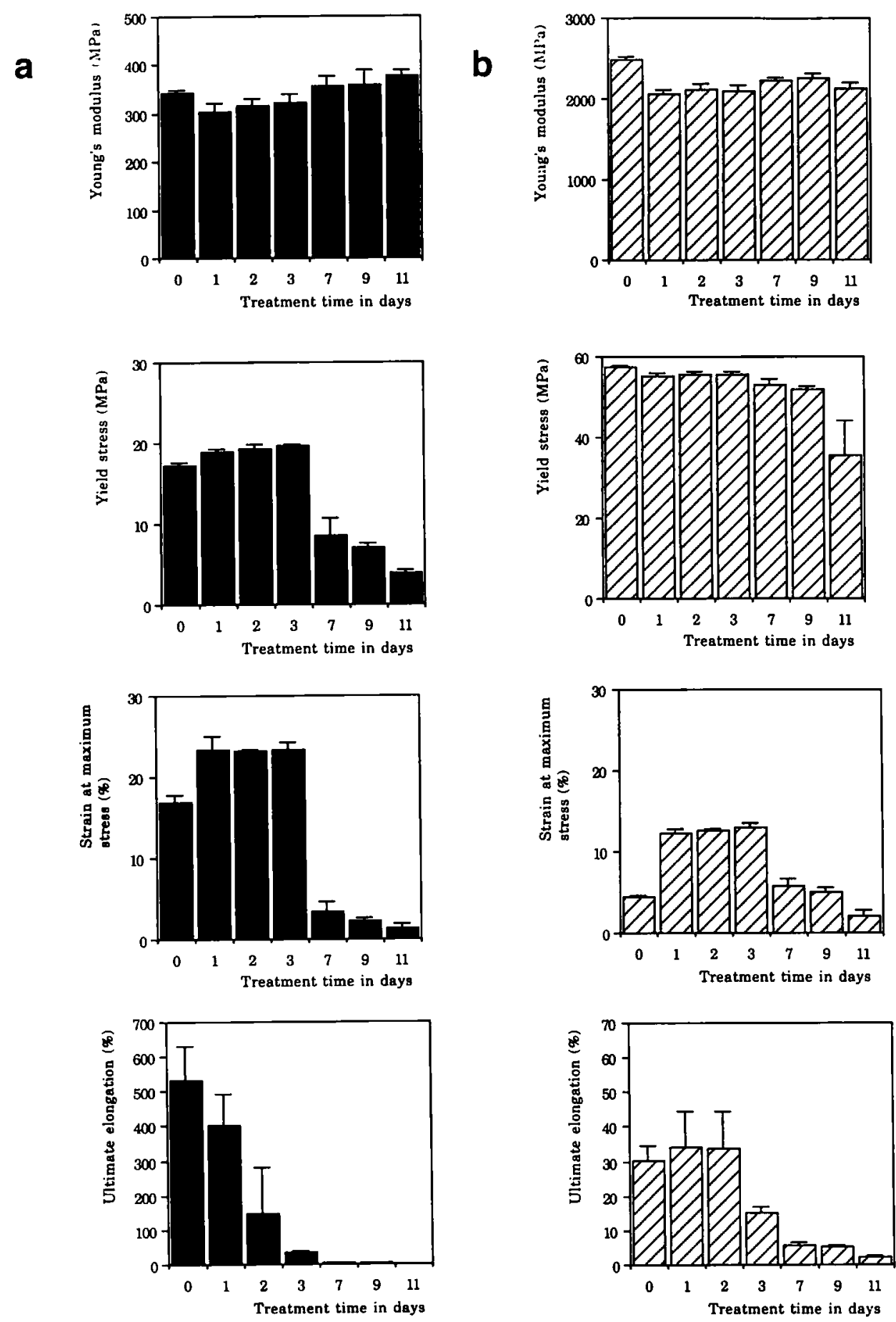

Figure 7 Tensile properties tersus water treatment time at $90^{\circ} \mathrm{C}$ : (a) P4GT-70/11; (b) PBT

are shown as a function of the treatment time. For comparison, the water uptake of PPVL after treatment with water at $71^{\circ} \mathrm{C}$ for $360 \mathrm{~h}$ was reported to be $0.62 \mathrm{wt} \%{ }^{10}$. As can be seen from Figure 6, a decrease in $\eta_{\text {rel }}$ was obtained for both polymers and the overall rates of hydrolysis (expressed in $\Delta \eta_{\mathrm{rel}} \mathrm{h}^{-1}$ ) were 0.0003 and 0.0010 for P4GT-70/11 and PBT, respectively.

The effect of water treatment on the mechanical properties of P4GT-70/11 and PBT was measured by conditioning test bars at $90^{\circ} \mathrm{C}$ in water, followed by determining the Shore-D hardness and tensile properties. It was found that the Shore-D hardness remained almost constant for P4GT-70/11 at 50-53 and for PBT at 67-70.

Figure 7 shows the tensile properties of P4GT-70/11 and PBT after conditioning at $90^{\circ} \mathrm{C}$ in water for various periods of time. The Young's modulus of both polymers remained almost constant, whereas the yield stress of P4GT-70/11 and PBT decreased after $264 \mathrm{~h}$ by 77 and $38 \%$, respectively. The strain at maximum stress increased after $24 \mathrm{~h}$ by 39 and $170 \%$, respectively, followed by a respective decrease after $264 \mathrm{~h}$ of 92 and $53 \%$. The initial increase may be caused by the presence of water molecules between the polymer chains, which thus served as a lubricant. The decrease in strain at maximum stress started after $72 \mathrm{~h}$ of treatment, which was in agreement with the pronounced decrease in $\eta_{\text {rel }}$ (as shown in Figure 6). The ultimate elongation of P4GT-70/11 and PBT after $264 \mathrm{~h}$ of treatment decreased to 0.2 and $7 \%$ of the initial values, respectively. Therefore, since the ultimate elongation decreased and in a later 
stage so did the yield stress, it can be concluded that hydrolysis occurred during conditioning at $90^{\circ} \mathrm{C}$ in water, which was in agreement with the results obtained from the viscometry measurements.

Considering the chemical structure of P4GT-70/11, two types of ester bonds are present (see Scheme l), i.e. the ester bond in the 4GT sequences and the ester bond between the 4G-PVL units and the 4GT sequences. In PBT, only ester bonds of the former type are present and it is known that PBT is relatively stable towards hydrolysis. From the above results regarding the stability upon conditioning with water at $90^{\circ} \mathrm{C}$, it is obvious that P4GT-70/11 was only somewhat less stable than PBT, which is in accordance with the fact that the ester bond in PPVL is known to be very stable to hydrolytic cleavage ${ }^{1,12}$.

The chemical stability of the $n$ GT-POn-based poly(ether ester)s is strongly dependent on the elastomeric segment, whereas the $n \mathrm{GT}$ segments are of less importance. The fact that the stability of the 4GT-PO4-based poly(ether ester)s is inferior to $\mathrm{PBT}^{4}$ reflects the influence of the PO4 segment. Since the PVL-based poly(ether ester)s resembled $\mathrm{PBT}$ with respect to the decay in mechanical properties upon conditioning at $90^{\circ} \mathrm{C}$ in water, these poly(ether ester)s were assumed to have a higher hydrolytic stability than the PO4-based polymers. Furthermore, due to the presence of the PO4 segments, the latter copolymers are subject to degradation by u.v. light, whereas the PVL-based poly(ether ester)s may be considered to be more stable, which is the case for copolymers with polyester amorphous segments instead of PO4 segments. In contrast to these poly(ester ester)s, the PVL-based poly(ether ester)s can be easily prepared and are not susceptible to randomization during synthesis.

\section{CONCLUSIONS}

Poly(ether ester)s were prepared from PVL, 4G and DMT via a two-stage melt process. Processing of a PVL-based poly(ether ester) was investigated after determination of the rheological and thermal properties of several of the PVL-based poly(ether ester)s mentioned above. Injection moulding of a PVL-based poly(ether ester), with $72 \mathrm{~mol} \% 4 \mathrm{GT}$ units, a melting temperature of $175^{\circ} \mathrm{C}$ and $M_{n} \sim 20000$, was studied and suitable moulding conditions were determined.

The stress-strain curve of the poly(ether ester) mentioned above showed three distinct regions, including the occurrence of strain-hardening. The tensile behaviour was related to the morphology of the poly(ether ester), i.e. a crystalline 4GT phase and an amorphous phase consisting of 4G-PVL units and non-crystallized 4GT segments. The influence of the relatively short $4 G-P V L$ segments was reflected in several of the properties, including the
Young's modulus and yield stress, resulting in the tough behaviour of the poly(ether ester): tensile break occurred after elongations higher than $500 \%$ at stresses of $\sim 20 \mathrm{MPa}$

As far as chemical stability was concerned, the PVL-based poly(ether ester)s were resistant towards treatment at room temperature with water or weakly acidic or alkaline solutions. Upon conditioning with water at $90^{\circ} \mathrm{C}$, a decrease in $\eta_{\text {rel }}$ was observed both for the PVL-based poly(ether ester) with $72 \mathrm{~mol} \% 4 \mathrm{GT}$ units and for PBT, with the former showing a slightly lower rate of hydrolysis. With respect to mechanical properties after conditioning with water at $90^{\circ} \mathrm{C}$, the Young's modulus and Shore-D hardness remained constant up to $264 \mathrm{~h}$, whereas other mechanical properties showed a decay only after $72 \mathrm{~h}$ of water treatment at $90^{\circ} \mathrm{C}$. Only the typical strain-hardening effect disappeared, while the elongation at break decreased drastically from 533 (initial value) via 404 (after $24 \mathrm{~h}$ ) to $36 \%$ (after $72 \mathrm{~h}$ of treatment). This decay in properties, which was also observed for PBT, was ascribed to the occurrence of hydrolysis. Based on the comparable behaviour of the poly(ether ester) and PBT with respect to the decay in mechanical properties, PVL-based poly(ether ester)s were assumed to have a higher hydrolytical stability than other poly(ether ester)s.

\section{ACKNOWLEDGEMENTS}

The authors would like to thank Mr L. P. G. Hawinkels (d.m.a.), $\mathrm{Mr}$ J. W. M. M. Hornesch (processing), $\mathrm{Mr}$ J. M. H. Linsen (mechanical properties) and Mr H. M. Schoffeleers (viscometry) from DSM Research for their experimental assistance.

\section{REFERENCES}

1 Witsiepe, W. K. ACS Adv. Chem. Ser. 1973, 129, 39

2 Hoeschele, G. K. and Witsiepe, W. K. Angew. Makromol. Chem. 1973, 29/30, 267

3 Perego, G., Cesari, M. and Vitali, R. J. Appl. Polım. Sci. 1984. 29. 1157

4 Schroeder. H. and Cella, R. J. in Encyclopedia of Polymer Science and Engineering (Eds H. F. Mark. N. M. Bikales, C. G. Overberger and G. Menges), Vol. 12. 2nd Edn. John Wiley. New York. 1988, p. 75

5 Quirk, R. P., Alsamarraie. M. A. and Schoenmaker, W in 'Handbook of Elastomers' (Eds A. K. Bhowmick and H. L. Stephens). Marcel Dekker, New York, 1988, p. 341

6 Tijsma. E. J., van der Does, L.. Bantjes, A., de Vries, N. K. Vulic. I. and Werumeus Buning. G. H. Macromolecules 1993. 26. 4845

7 Tijsma. E. J., van der Does, L., Bantjes, A., Vulić, I. and Werumeus Buning. G. H. Macromolecules 1994, 27, 179

8 Raju, K. V.S. N. and Yaseen, M. J. Appl. Polım. Sci. 1992, 45, 677

9 IJzermans, A. B., Pluijm, F. J., Huntjens, F. J. and Repin, J. F. Br. Polym. J. 1975, 7, 211

10 Paul, C. W. J. Appl. Polym. Sci. 1988, 36, 675

11 Oosterhof, H. A. Polymer 1974, 15, 49

12 Mayne, N. R. CHEMTECH 1972, 728 